\title{
CLINICAL, EPIDEMIOLOGICAL, AND VIROLOGICAL ASPECTS OF ECHOVIRUS TYPE 9 INFECTION IN SHEFFIELD, 1960
}

\author{
BY \\ D. HOBSON, J. M. HOSKINS, AND J. HORNER \\ University of Sheffield Virus Research Laboratory, Lodge Moor Hospital, Sheffield \\ AND \\ A. H. CLARKE AND F. B. G. WOOD \\ General Practitioners, Sheffield
}

In the summer of 1960 , a number of patients from Sheffield, and the surrounding districts were admitted to hospital with clinical evidence of acute meningitis. The studies described below showed that the causative agent most commonly incriminated was echovirus type 9 , a virus not encountered in Sheffield during the previous 3 years.

The association of this particular virus with aseptic meningitis, often accompanied by a rubelliform rash, was first observed in 1956 (Tyrrell and Snell, 1956; McLean and Cameron, 1957). On many subsequent occasions frank epidemics of meningitis, sharply circumscribed in time and place, have occurred with evidence of direct spread within families (Sanford and Sulkin, 1959; Sabin, Krumbiegal, and Wigand 1958; Sabin 1960).

In 1956, a brisk localized outbreak of echovirus type 9 infection occurred near Sheffield (Tyrrell, Lane, and Snell, 1958), and a similar but smaller episode occurred in this region in 1957 (Heath, unpublished).

In the 1960 outbreak, cases of meningitis continued to appear sporadically during a 3-month period from widely-separated areas. There appeared to be no direct contact between the patients themselves except for certain intrafamilial episodes detailed below; in fact, no single general practice in which meningitis occurred contributed more than one family to the hospital.

In view of these recurrent events and the patchy nature of the 1960 outbreak, it seemed possible that echovirus type 9 was being transmitted to susceptible persons by asymptomatic carriage through a partially-immune population. An alternative possibility was that frank cases of meningitis represented only one variety of the clinical manifestations of echovirus type 9 infection, whilst the main reservoir and the bulk of virus spread might exist in some less easily recognized non-meningeal illness not normally seen in hospital practice.

Because of these possibilities, virus studies were made in all members of the families in which a presumed case of echovirus infection occurred, on milde illnesses seen in a representative urban general practice over the same period of time, and also on healthy persons in the general population.

Certain laboratory characteristics of echovirus type 9 strains recovered from different sources were examined to determine whether differences in their pattern of infection might be explained by variations in the biological properties of the virus.

\section{Materials AND Methods \\ LABORATORY METHODS}

Throat swabs and faecal specimens were collected, stored, and processed for examination in tissue culture as described by Hoskins, Hobson, Udall, Madland, Goffe, Stuart-Harris, and Hertzog (1962). Primary rhesus monkey kidney (MK) tissue cultures were prepared as described by Hoskins and others (1962), and HEp 2 cultures as indicated by Hobson and Schild (1960).

Specimens of cerebrospinal fluid (C.S.F.) were inoculated into four MK tubes in 0.5-ml. amounts per tube. Throat swab and faecal extracts were examined by standard routine methods (Hoskins and others, 1962).

Serum neutralization tests were performed in MK tubes. Serial dilutions of serum in Hanks's saline were mixed with equal volumes of a virus suspension calculated to contain $100 \mathrm{TCD}_{50}$ per $0.1 \mathrm{ml}$. The mixtures were incubated at room temperature for 
1 hour, $0 \cdot 2-\mathrm{ml}$. volumes then being inoculated into each of four tissue culture tubes. The tubes were read daily for 9 days, and the neutralization titres were calculated (Reed and Muench, 1938) from the final pattern of virus growth.

Suckling mice were inoculated without anaesthesia, and received $0.01 \mathrm{ml}$. of tissue culture fluid intracerebrally and $0.02 \mathrm{ml}$. into the dorsal fat pad. They were observed daily for evidence of paralysis.

\section{Methods of Family Study}

Each patient seen in hospital with meningitis, or in general practice with other types of illness, was recorded as an "index patient". Throughout his illness and during his convalescence, wherever possible, the whole family of the index case was visited frequently at home. Throat swabs and faeces were obtained at the first visit, and venous blood taken from the older family members. A complete history was taken of illnesses in the family or family contacts over 3 weeks before the index illness. If subsequent illnesses occurred in any member of the family, further clinical specimens were taken, and the time and type of illness in relation to that of the index case was noted. Second samples of blood were taken 2 weeks after the first specimen.

Serum was also obtained from children in normal health or with non-infective illnesses, and from healthy women attending routine antenatal clinics. These were compared with sera from patients with meningitis or exanthematous illness, from healthy contacts of such illness, and from adults with various illnesses mentioned below.

In these studies, the clinical accounts given for various types of illness are confined to those patients from whom virus was recovered, and do not include data from secondary cases in the family or illnesses in other families where the aetiology could not be proven by virus isolation. The importance of keeping this distinction between proven and presumed cases of echovirus infection has been stressed by Sabin (1960).

\section{RESULTS}

\section{Aseptic Meningitis}

47 patients were investigated (Table I); in 28 instances faeces, throat swabs, and C.S.F. were all examined in tissue culture, in a further ten patients only faeces were available, and in the remaining nine only C.S.F.

Echovirus type 9 was isolated from twelve patients; C.S.F. cultures were positive in three instances where faeces and throat swab also yielded virus and in two from whom no other samples were available.

The clinical features in these twelve patients were those of a simple meningitis with a sudden onset of frontal headache or back-pain 12 to 24 hours before admission to hospital. Vomiting was prominent initially in four patients, but none had any diarrhoea. There was no evidence of prodromal illness or convulsions. Four patients complained of sore throat, but in none was there any enlargement of cervical lymph-nodes, nor was any exanthem or enanthem seen. Although slight neck stiffness was the only abnormal clinical finding, definite changes in the C.S.F. were found in all patients, with a slight increase in pressure and protein and a pleocytosis of between 100 and 5,000 cells, mainly lymphocytes. There were no changes in chloride or sugar concentrations in the C.S.F.

TABLE I

DISTRIBUTION OF INFECTION WITH ECHOVIRUS TYPE 9 IN VARIOUS CLINICAL CATEGORIES

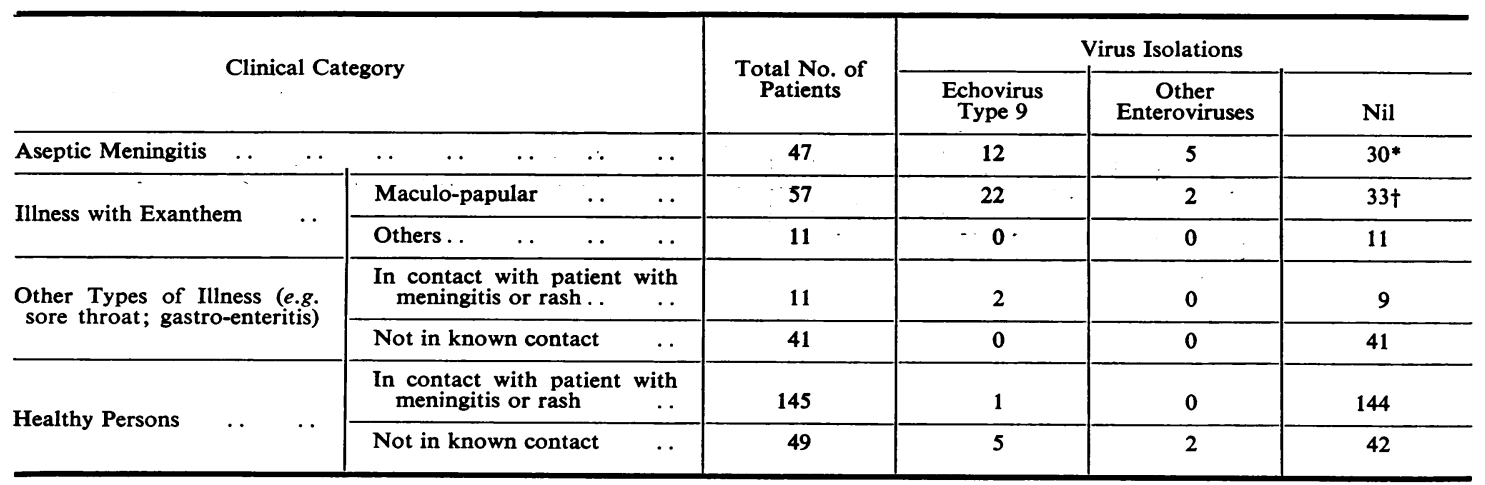

* Five patients were in families with known echovirus type 9 infections.

† One patient was in a family with known echovirus type 9 infections. 
Eleven of the twelve patients yielding echovirus type 9 were under 16 years of age (Fig. 1).

The first was admitted to hospital in July and the last in November, 1960 (Fig. 2, opposite). Three of these patients were siblings. In two further families, secondary cases of meningitis occurred; in one of these, the brother and two sisters of the index patient were all admitted to hospital later in the same week, and in the other a brother was admitted 4 days after the index patient. No viruses were isolated from any of these secondary illnesses. However, the close clinical similarities between these patients and the index member of the family, and the short interval between their illnesses, suggested exposure to a common infective agent of short incubation period. Six other members of these two families remained in normal health; viruses were not isolated from them, nor from any member of four other families in which no secondary illness occurred.

One patient with meningitis, from whom no virus was isolated, had a 3-month-old son who had been at home 10 days earlier with a mild illness with a rubelliform rash. Echovirus type 9 was isolated from faecal specimens of this child, but not from the father who had remained well.

Thus, twelve of the 47 patients with meningitis had a definite infection with echovirus type 9 and a further five had a close family contact with a person yielding the same virus.
In the remaining thirty patients $(63.8$ per cent. of the group investigated) there was no evidence of echovirus type 9 infection in either patient or family. Five of these patients were clinically very similar to the group described above: poliovirus type 3 was isolated from one, another yielded a Coxsackie Group B virus, and unidentified enteroviruses were recovered from the remaining three.

In 25 cases ( $53 \cdot 2$ per cent. of the total group) no viruses could be incriminated either in the index patient or in other members of the family. Three patients showed photophobia and behavioural changes suggestive of encephalitis, and all had a recent preceding history of measles. Six others were adults with diverse clinical features unlike those found in echovirus-positive patients (e.g. dysuria, paraesthesiae, or mental confusion) but resembling those shown in mumps meningo-encephalitis. In seven of the 25 cases, specimens of faeces were not available for examination.

\section{EXANTHEMATOUS ILLNESSES}

While these studies with aseptic meningitis were in progress, two family illnesses were investigated with the kind co-operation of their medical adviser, Dr. C. E. Naish.

In the first family, two children had been admitted to another hospital with meningitis unaccompanied by any other clinical manifestations; echovirus type 9 .

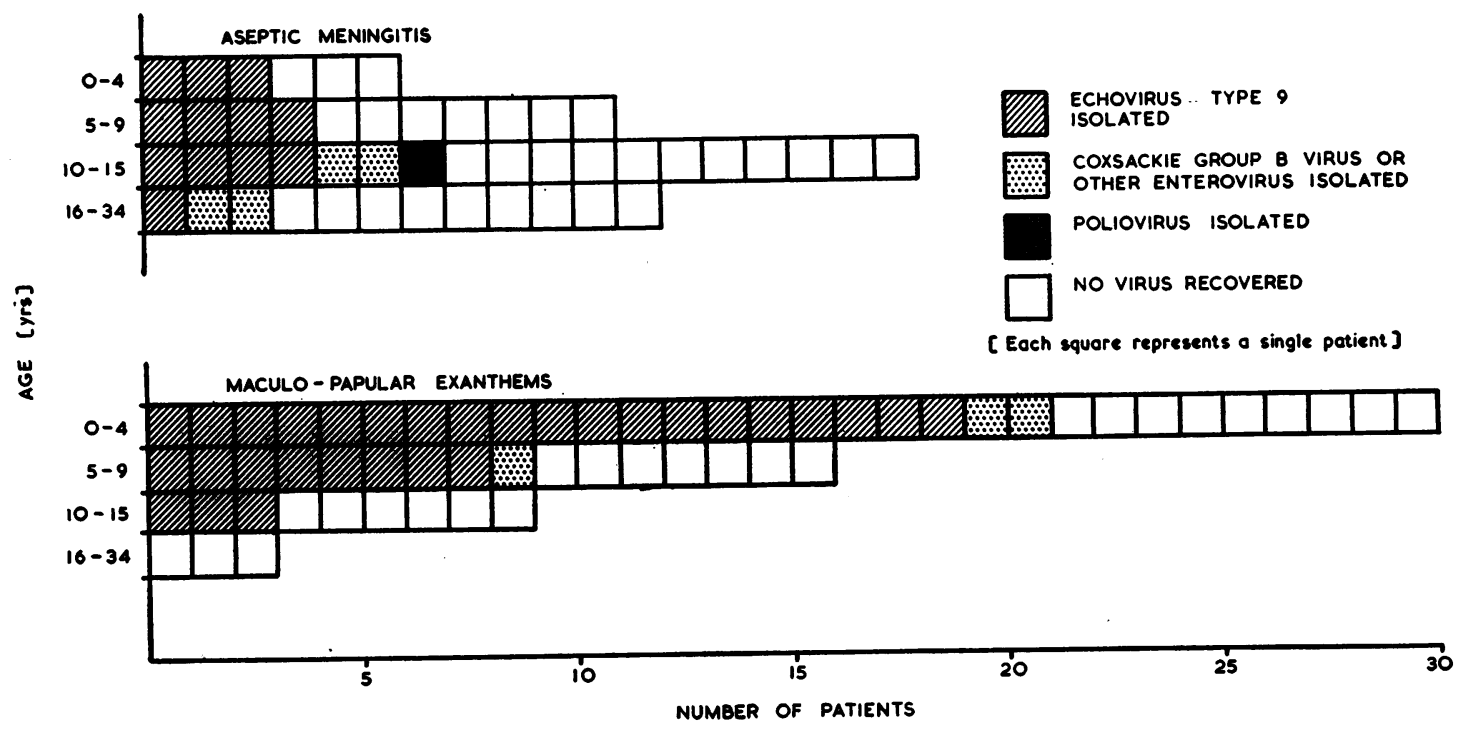

FIG. 1.-Age distribution of patients with meningitis and exanthematous illness. 

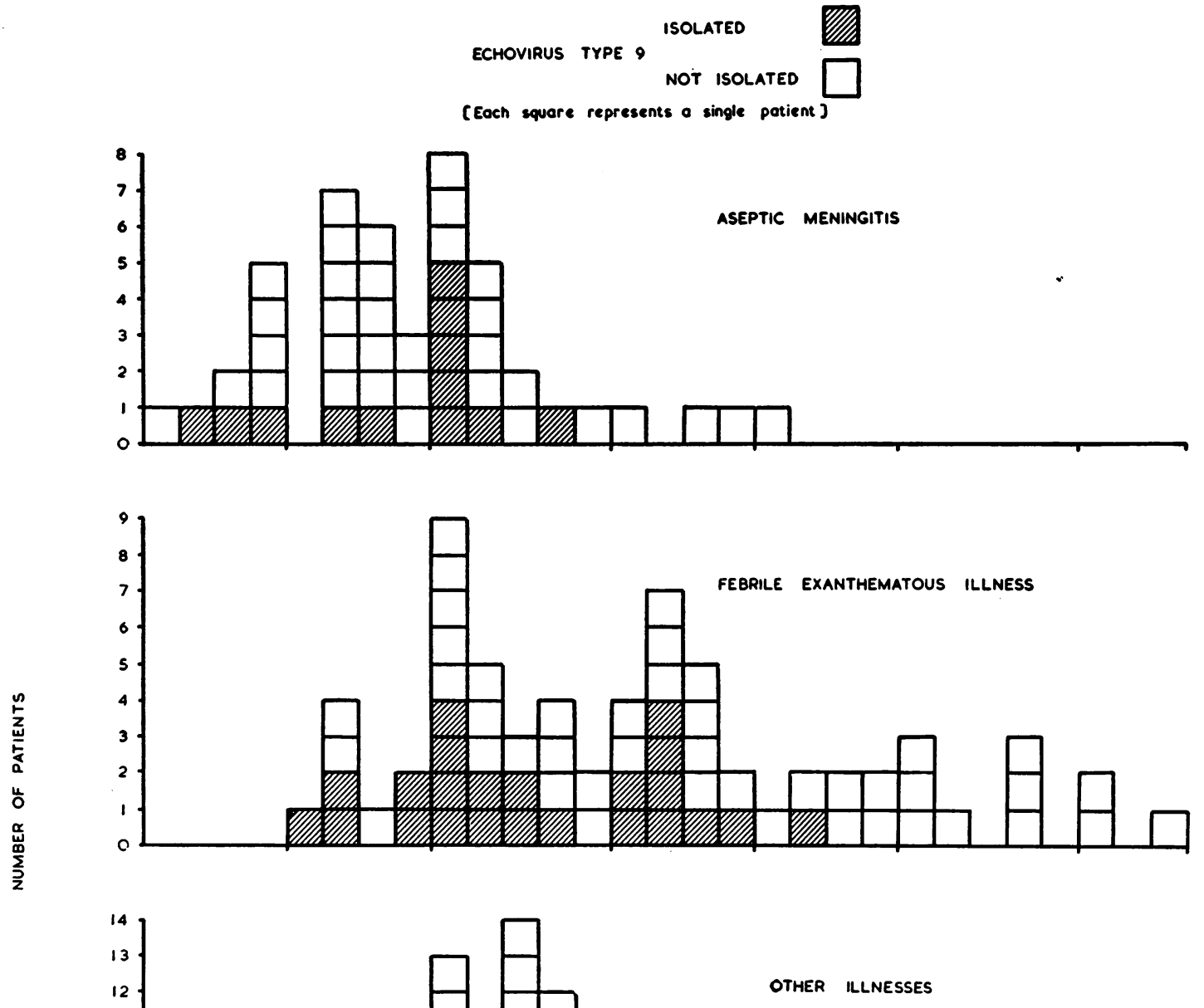

Fig. 2.-Weekly incidence of meningitis, exanthematous illness, and other illness in relation to isolation of echovirus type 9. 
was recovered from the throat swab of one of these children (Gillespie, personal communication). Other members of this family were seen at home: the mother was well, but the father had severe headache, back-pain and sore throat, and three of the four remaining children had been vaguely unwell in the preceding 2 weeks, with a "food-rash" in one child. Echovirus type 9 was recovered from the faeces and throat swabs of two children.

In the second family, an 8-year-old girl had severe headache and slight neck stiffness; there were no other abnormal findings and she was ambulant at home. Her brother, aged 4 years, appeared healthy but had a faint maculo-papular rash confined to the trunk, lasting 3 days. Echovirus type 9 was isolated from the faeces and throat swabs of both children, but not from their parents.

In the first week of August, 1960, a small group of children under the care of one of us (AHC) at a long-stay orthopaedic hospital became ill. None showed evidence of meningitis. They were fretful, with a low-grade pyrexia $\left(99-100^{\circ} \mathrm{F}\right.$.), and some had a transient maculo-papular rash. Echovirus type 9 was isolated from four of seven children with a recent rash, but not from four children with mild disorders unaccompanied by a rash. In the preceding month several nurses in the same hospital had reported vomiting and malaise. When examined retrospectively none yielded enteroviruses, and only two of ten nurses had neutralizing antibody against echovirus type 9; titres were below $1 / 16$ in both cases.

One ward in this hospital, containing two children with echovirus infection, had been under daily surveillance from April to June, 1960, in connexion with a poliovirus vaccination programme (Hoskins and others, 1961) but no evidence of echovirus type 9 infection had been found during that period.

In contrast with the patients with meningitis, the illness associated with echovirus type 9 infection in these small children was transient and ill-defined, and it seemed probable it might pass without recognition in the general population. Accordingly, the inquiry was extended to a typical urban general practice (A.H.C. and F.B.G.W.). The general plan was to study every child with a rash in the practice and to observe the whole family of each patient clinically and virologically for evidence of other manifestations or asymptomatic virus carriage.

Sixty families were examined, comprising 105 adults and 100 children. The results are summarized in Table II, and the rate of recovery of echovirus type 9 was compared with that in meningitis and other conditions in Table I. In 49 families, the index patients were children with a maculo-papular rash, and from fifteen of these patients echovirus type 9 was isolated from faeces or throat swab. 21 other members of these fifteen families became ill within a few days of the index patient; fourteen illnesses were in other children and seven in adults, and in eight cases the illness was accompanied by a rash like that of the index patient. Echovirus type 9 was recovered from nine of the ill children, two of whom had an influenza-like illness without rash. Only one healthy person in these fifteen families yielded echovirus type 9.

The clinical features in the 22 patients with a rash from whom echovirus type 9 was recovered are listedo in Table III (opposite); 14 were less than 5 years old? and only three were over 10 years of age. Prodromal symptoms occurred in fifteen patients; in young children, fretfulness was the earliest effect; mild diarrhoea was common and a few of the older children vomited several times. Most children showed some pharyngitis, and occipital or cervical lymph-nodes were palpable though not so greatly enlarged or as tender as in typical rubella. These prodromal features lasted for 1 to 6 days before the rash appeared. Nine children were apyrexial throughout the illness, six were febrile during the period after the rash appeared. In most febrile cases, there

TABLE II

INCIDENCE OF ECHOVIRUS TYPE 9 INFECTION IN SIXTY FAMILIES WITH EXANTHEMATOUS ILLNESS

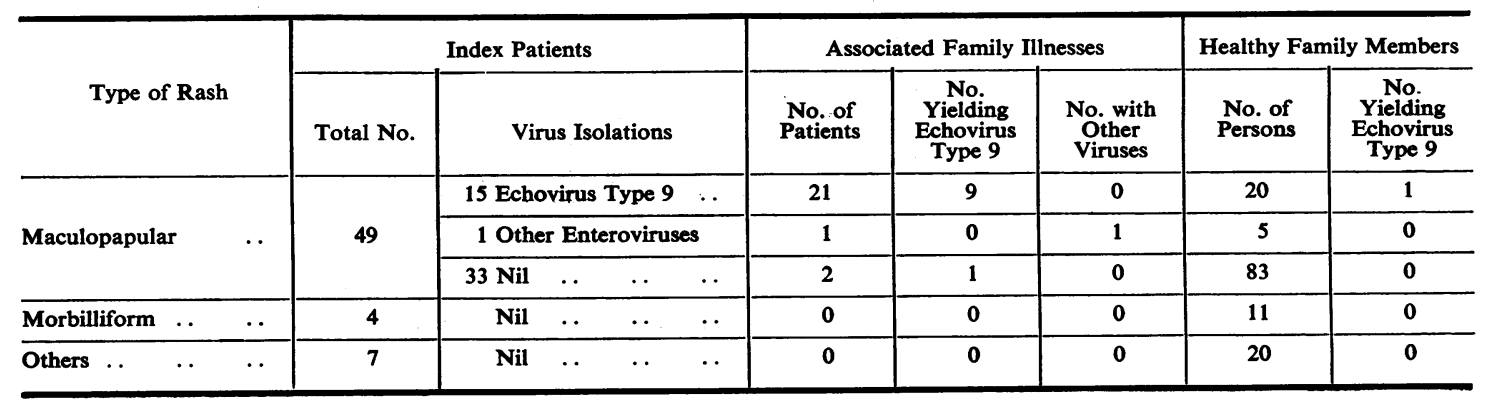


TABLE III

CLINICAL FEATURES OF 57 PATIENTS WITH ILLNESS ASSOCIATED WITH A MACULO-PAPULAR RASH

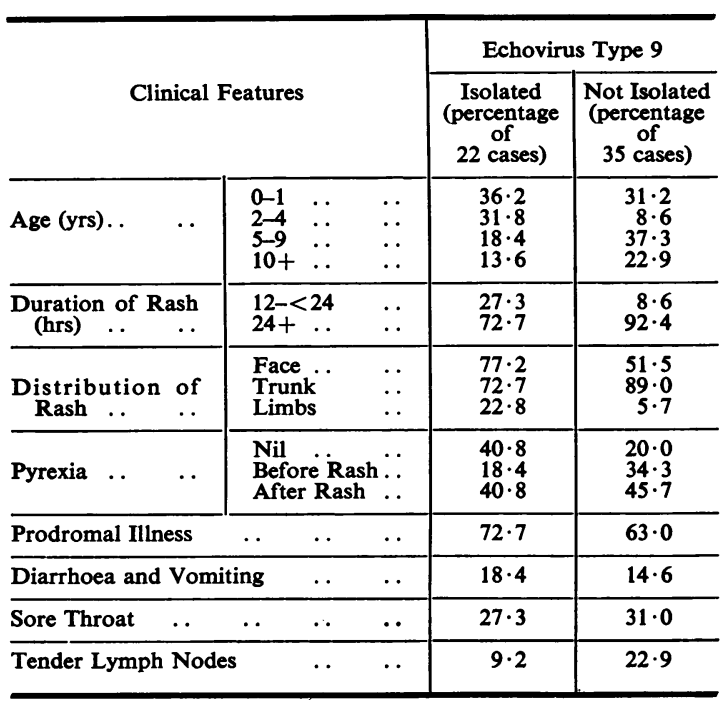

was only low grade pyrexia for 2 to 3 days, but in a few children the temperature rose to $102^{\circ} \mathrm{F}$.

The rash was pink, and often blotchy; the trunk and limbs were less constantly involved than the face. The lesions, often sparsely scattered, were macules or papules usually less than $5 \mathrm{~mm}$. diameter, appearing as a single crop and fading after 12 to 72 hours without desquamation or staining.

In three patients shallow ulcers with a red areola were seen inside the lips and under the tongue; these did not resemble Koplik spots, and no lesions were seen on the soft palate as in herpangina.

One-third of the children, mainly those under 2 years of age, were brought to our notice only because of the rash, but remained quite well throughout. Two children had a biphasic illness, developing a rash with the second wave of fever. None of these patients developed meningeal symptoms.

There were 34 other families containing index patients with a maculo-papular rash; in one of these a Coxsackie group B virus was isolated from two children with similar illnesses. In none of the other 33 index patients was any virus isolated; secondary illnesses occurred only in two families, with a similar rubelliform rash in both cases. Echovirus type 9 was isolated from one of these children, but from no member of any other family. Neutralizing antibody to echovirus type 9 was found only in two adults, who had titres of $1 / 8$ only.

There were no clear-cut features allowing clinical differentiation of echovirus type 9 infections with rash from the rest (Table III), nor did the proven virus infections occur in a period of time sharply demarcated from the exanthematous illnesses with negative virological findings (Fig. 2). There was, however, a marked difference in the secondary attack rate between families containing index patients with definite echovirus type 9 infection and those of no proven aetiology (Table II); the former families provided 21 associated illnesses with recovery of echovirus in nine persons, as compared with only two associated illnesses and one recovery of echovirus type 9 from the latter.

In the latter group, it is possible that some of the exanthematous illnesses were, in fact, missed cases of infection with echovirus type 9 or other echoviruses known to cause maculopapular exanthems (see Sabin, 1960). The young age of most of the index patients and considerations of family medical practice limited further assessment by serological means. However, it seems possible that some patients in this group were not undergoing infection but had in fact developed a rash, as many of their mothers believed, as part of a mild disorder associated with teething, feeding-irregularities, or undue sweating. The small number of secondary illnesses in these families would support this view. In none of the families was there any convincing clinical evidence that rubella could be implicated.

Other categories of acute exanthematous illnesses seen in the practice (Table II) included four cases with a morbilliform rash and coryza, diagnosed as measles, two families containing single cases of erythema multiforme, and two families with vesicular symptoms thought to be due to chickenpox. No viruses were recovered from the index patients or their relatives, and none of eight parents had detectable neutralizing antibody to echovirus type 9.

\section{Other Clinical Conditions}

From the same general practice, as many other types of acute illness as possible were studied concurrently with the meningeal and exanthematous illnesses. 41 families were seen (Fig. 1), containing twenty patients with acute diarrhoea and vomiting, seventeen with sore throat and pharyngitis, and seven children with upper respiratory tract infections. No viruses were isolated from 28 adults or 34 children.

\section{Studies in the Healthy Population}

Since most of the echovirus type 9 isolations came from small children, similar investigations were made in apparently normal children from similar areas of 
Sheffield and attending nursery schools. With the kind co-operation of Dr. Llewelyn Roberts and the staff of the City of Sheffield Department of Health, faecal specimens were examined from 49 children between 2 and 5 years old. Echovirus type 9 was isolated from five children, and Coxsackie group B virus from two others. None had any history of illness in the previous three weeks.

\section{SEROLOGICAL INVESTIGATIONS}

Initially, neutralization titrations were performed with the prototype Hill strain of echovirus type 9. Little evidence of specific antibody could be found, even in convalescent sera from patients with meningitis.

It seemed possible that the Hill strain was failing to detect antibody induced by the 1960 infective strains because of differences in antigenic constitution or avidity. Hence, parallel neutralization tests with Hill virus and recently isolated strains were made under various conditions with human sera and a monkey antiserum prepared against Hill virus. The recent virus strains detected higher antibody titres than Hill virus in the patient's sera (Table IV), although the Hill strain detected a higher titre in the homologous monkey antiserum. These results do not show whether the difference between the 1960 strains and Hill virus is qualitative or quantitative. However, increasing the period of virus-serum interaction from 1 hour to 4 hours, or incubating at $37^{\circ} \mathrm{C}$. rather than at room temperature, did not enhance antibody titres detected by Hill virus more than two-fold.

With these differences in mind, neutralizing antibody levels in all patients' sera in the groups described above were titrated with a single virus, strain $169 / 60$, recovered from a patient with meningitis (Table V).

Antibody levels were low and infrequent in healthy children or adults not exposed to infection, and in adults with various illnesses not associated with carriage of echovirus type 9. However, the apparently healthy contacts of patients with known echovirus infections showed neutralizing antibody in more instances, and with a somewhat higher mean titre.

Only seven sera were available from patients with a rash; two contained neutralizing antibody, with titres of $1 / 11$ and $1 / 166$ respectively.

The group of patients with meningitis showed the highest mean titre (1/59), and neutralizing antibody was present to titres of $1 / 16$ or greater in ten people with the typical clinical picture of echovirus infection but with no virus isolation. In seven instances in which paired sera were available, high antibody titres were found in both specimens with no significant rise during the course of the meningitis. This

\section{TABLE IV}

COMPARISON OF NEUTRALIZING ANTIBODY TITRES IN SERA, DETECTED BY (a) A SHEFFIELD, 1960, STRAIN OF ECHOVIRUS TYPE 9, AND (b) THE PROTOTYPE HILL STRAIN

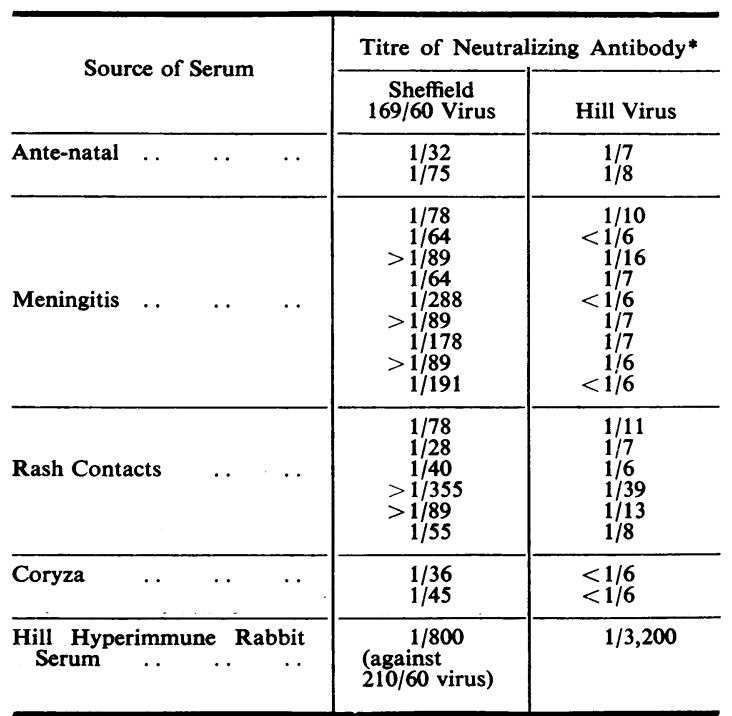

* $100 \mathrm{TCD}_{\mathrm{so}} / 0.1 \mathrm{ml}$. of each virus incubated for $1 \mathrm{hr}$ at room temperature.

TABLE V

DISTRIBUTTION OF NEUTRALIZING ANTIBODY AGAINST ECHOVIRUS TYPE 9 (STRAIN 169/60) IN VARIOUS CLINICAL CATEGORIES

\begin{tabular}{|c|c|c|}
\hline Clinical Category & $\begin{array}{l}\text { No. of Patients } \\
\text { with } \\
\text { Titres }>1 / 10 \\
\text { in Either } \\
\text { Serum Sample }\end{array}$ & $\begin{array}{c}\text { Geometric Mean } \\
\text { Titre in Patients } \\
\text { with } \\
\text { Titre }>1 / 10\end{array}$ \\
\hline Healthy Children (0 to $8 \mathrm{yrs}$ ) & $0 / 25$ & - \\
\hline Healthy Adults (ante-natal) & $\begin{array}{c}4 / 32 \\
(12 \cdot 5 \text { per cent. })\end{array}$ & $1 / 27$ \\
\hline Adults with Various Illnesses & $\begin{array}{c}3 / 25 \\
(13 \cdot 0 \text { per cent. })\end{array}$ & $1 / 26$ \\
\hline Contacts of Cases with Rash & $\begin{array}{c}15 / 22 \\
(68 \cdot 2 \text { per cent. })\end{array}$ & $1 / 38$ \\
\hline Illness with Rash . . & $\begin{array}{c}2 / 7 \\
\text { (28.6 per cent.) }\end{array}$ & $1 / 43$ \\
\hline $\begin{array}{lll}\text { Meningitis } \quad \ldots & \ldots\end{array}$ & $\begin{array}{c}17 / 29 \\
\text { (58.6 per cent.) }\end{array}$ & $1 / 59$ \\
\hline
\end{tabular}

suggests that antibody production had begun during a subclinical period of virus multiplication, preceding the onset of overt meningeal symptoms.

\section{LABORATORY CHARACTERISTICS OF ECHOVIRUS TYPE 9 STRAINS ISOLATED IN 1960 \\ The investigations reported above yielded twelve strains of echovirus type 9 from patients with}


meningitis, 22 strains from children with a milder illness characterized by a rubelliform rash, and five strains from apparently healthy children not in known contact with disease.

It seemed of interest to determine whether virus strains isolated from these three distinct groups of persons were significantly different and could be distinguished in the laboratory. It is known that poliovirus strains isolated from different epidemics may show such differences (Habel and Silverberg, 1957), and that strains from healthy carriers or nonparalytic cases may behave differently from those isolated from paralytic cases. Similarly, known attenuated strains of poliovirus can be distinguished from virulent prototype strains by a variety of genetic markers (Vogt, Dulbecco, and Wenner, 1957; Sabin 1959; McBride, 1959).

The prototype Hill strain of echovirus type 9 (Ramos-Alvarez and Sabin, 1954), which was isolated from a healthy child, was compared with Sheffield strains from each type of patient.

Regardless of their origin, all the 1960 strains were virulent for suckling mice after intracerebral inoculation. In general, as reported by Eggers and Sabin (1959) results with faecal extracts were variable, possibly because of their low virus content, but tissue culture fluids of the first virus passage consistently produced a progressive flaccid paralysis. The exact age of the litter of mice at the time of inoculation was found to affect the number of animals paralysed, and the extent and outcome of the paralysis. Strains of virus which caused a rapidly extending paralysis of all mice in 1-day-old litters, ending with death in quadriplegia in 6 to 8 days, were often found to produce only slight degrees of paralysis in a few mice in 4-day-old litters amongst which complete recovery was common.

Some litter-to-litter variation was found with several strains of virus, inoculated in standardized dilutions. However, when titrations were repeated in larger groups of mice less than 24 hours old, which had been pooled and randomly redistributed, differences in virulence were found of up to 50 -fold, but all the 1960 strains were considerably more virulent than the prototype Hill strain, which failed to cause paralysis or death in any experiment. The least virulent of the Sheffield strains gave a $T_{C D} D_{50}: L_{50}$ ratio of $6.8 \times 10^{3}: 1$.

Representative Sheffield strains were not virulent for adult mice by intracerebral, intraperitoneal, or intravenous injection. Although the apparent virulence of these strains for suckling mice was greater the less the litter-age, intravenous injection of pregnant mice in the first, second, and final week of pregnancy did not cause any intra-uterine deaths, foetal malformations, or post-natal effects.

Neither the Hill strain nor the Sheffield strains grown in MK tissue culture produced cytopathic changes in monolayers of HEp II cells. Furthermore, the same strains were unable to yield plaques when plated on agar/ERK cell suspensions (Hoskins and others, 1961).

Representative Sheffield strains and Hill strain were titrated in MK tubes at both $37^{\circ}$ and $40^{\circ} \mathrm{C}$., to determine whether there was any difference in growth characteristics which could be correlated with variation in mouse virulence. In fact, no significant differences in virus growth at the two temperatures was observed, titres at $40^{\circ} \mathrm{C}$. being uniformly $<0.8 \log _{10}$ lower than those at $37^{\circ} \mathrm{C}$.

\section{Discussion}

In many previous outbreaks of echovirus type 9 infection, epidemicity appears to have been high, and infection has resulted in overt clinical disease in most instances, usually in the form of meningitis, with a rubelliform rash as an inconstant additional feature. Healthy carriers or subclinical infections seemed to be uncommon (Sabin and others, 1958; Sanford and Sulkin, 1959).

Certain differences from this epidemiological pattern were found in the present investigation. In adults and older children, healthy carriers or persons with trivial or latent disease were infrequent, as with Sabin and others (1958). Meningitis appeared to be the sole expression of disease, and these events occurred sporadically throughout the area.

In small children, however, the picture was entirely different. Echovirus type 9 was recovered with greater frequency than from adults, from quite trivial infections often associated with a transient rash but with no signs of meningeal involvement. In many instances these illnesses could not have been differentiated clinically from the so-called teething disturbances or feeding disorders commonly seen in infancy in general practice.

Infection seemed to spread readily from child to child within families, and virus was often recovered from siblings who might never have been brought to notice except under the conditions of the present family study. Moreover, excretion of echovirus type 9 was found in five (10 per cent.) of a group of nursery-school children, none of whom had had reported illness within the previous 3 weeks.

In fact, the rate of infection, and both the probability and pattern of clinical effects, showed a striking dichotomy according to age. It is interesting to consider these broad epidemiological features in relation to other factors which emerged during the present investigation. 
The small number of adult infections was not due merely to a lack of opportunity for exposure to the virus, since many of the adults were parents of families in which echovirus type 9 was clearly being transmitted readily from child to child. This apparently low susceptibility did not seem to be due to specific immunization resulting from previous exposure to echovirus type 9 . In fact the induction of specific neutralizing antibody by this agent, even in patients with meningitis, appeared to be poor in comparison with titres commonly found during recovery from poliomyelitis. A distinct difference was found between antibody titres determined by the prototype Hill strain and by strains recently isolated from infection. It seems possible that differences in epidemicity between various strains of echovirus type 9 may be associated with differences in their antigenic constitution.

However, the sharp differences in the clinical manifestations of echovirus type 9 infection in the 1960 outbreak did not seem to be governed by differences between the various strains of virus. Strains recovered from the faeces of apparently healthy carriers showed no clear-cut distinctions from those isolated directly from the cerebrospinal fluid of patients with frank meningitis, and were as highly virulent as the meningeal strains on inoculation into mice.

It is interesting to compare the behaviour of the virus in human populations with that in mice. In both cases, increasing age appears to confer a decreased susceptibility to infection regardless of past experience. It may be implied from the studies of Eggers and Sabin (1959) that the tissues of newborn mice offer a better milieu for virus proliferation than do those of older mice, and it would be profitable to study further the biochemical, hormonal, or immunological changes which contribute to this phenomenon.

It seems possible that echovirus type 9 infection might be maintained in the pre-school population for long periods of time in a form which is seldom brought to the notice of specialized hospitals with virological facilities. The infectivity of the virus probably falls steeply for persons of increasing age, but in the comparatively few who remain susceptible to infection, clinical manifestations appear to be the rule. The relative susceptibility of different tissues may also vary with age to produce a neurological rather than a dermatological syndrome.

It seems unlikely from the results described above that the differences in infective pattern are due to obvious genetic differences in the virus strains themselves. The nature of intrinsic host factors which may modify the expression of virulence of enteroviruses is a field which has received comparatively little study since the advent of potent vaccines, but a consideration of such factors may be desirable when the apparent success of programmes of universal vaccination is being assessed.

\section{SUMMARY}

Echovirus type 9 virus was found in association with a mild non-meningeal illness of small children accompanied by a rubelliform rash, or in aseptic meningitis affecting older children and adults. There appeared to be little overlap between the two forms of clinical disease. Very few virus isolations were made from other types of illness or from healthy adults. The possibility that many adult illnesses are derived from a reservoir of infection in small children is discussed. There was little evidence of immunization by previous virus exposure in the normal gener al population. Virus strains isolated from various types of patient appeared to show little difference in laboratory behaviour. The possible role of host factors in the infectivity and virulence of echovirus type 9 is discussed.

\section{REFERENCES}

Eggers, H. J., and Sabin, A. B. (1959). J. exp. Med., 110, 951.

Habel, K., and Silverberg, R. J. (1957). J. Immunol., 79, 294.

Hobson, D., and Schild, G. C. (1960). Brit. med. J., ii, 1414.

Hoskins, J. M., Hobson, D., Udall, V., Madland, T., Goffe, A. P., Stuart-Harris, C. H., and Herzog, E. G. (1962). Brit. med. J., 1, 747.

McBride, W. D. (1959). Virology, 7, 45.

McLean, D. M., and Cameron, D. (1957). J. Hyg. (Camb.), 55, 464.

Ramos-Alvarez, M., and Sabin, A. B. (1954). Proc. Soc. exp. Biol., N.Y., 87, 655.

Reed, L. J., and Muench, H. (1938). Amer. J. Hyg., 27, 493.

Sabin, A. B. (1960). In "Viral Infections of Infancy and Childhood", ed. H. M. Rose. Symp. No. 10, p. 78. Section on Microbiology, N.Y. Acad. Med. HoeberHarper, New York.

, Krumbiegel, E. R., and Wigand, R. (1958). A.M.A. J. Dis. Child., 96, 197.

Sanford, J. P., and Sulkin, S. E. (1959). New Engl. J. Med., 261, 1113.

Tyrrell, D. A. J., Lane, R. R., and Snell, B. (1958). Quart.J. Med., $27,323$.

and Snell, B. (1956). Lancet, 2, 1028.

Vogt, M., Dulbecco, R., and Wenner, H. A. (1957). Virology, 4, 141. 